\title{
Proksimale Migrate olan Taşlı Double-J Kateterin Fleksible Üreterorenoskopi ile Tedavisi
}

\author{
Hakan Kılıçarslan, Onur Kaygısız, Sinan Çelen, Feyzi Mutlu Kanat
}

Uludağ Üniversitesi, Tıp Fakültesi, Üroloji Anabilim Dalı, Bursa

\section{Giriş}

$\mathrm{D}$ ouble-J kateterler üriner diversiyon, postoperatif drenaj, ağrı palyasyonu, obstrüksiyonun giderilmesi amaciyla kullanılabilmektedir. Stent yardımıyla double-j kateterlerin yerleştirilmesinin tanımlanmasıyla birlikte üriner sistemle ilgili bir çok patolojide tercih edilmeye başlanmıştır (1). Yaygın kullanımıyla birlikte kateter komplikasyonlarıyla daha sık karşılaşmaktayız. Kateter migrasyonu bu komplikasyonlar içinde sık görülenlerindendir $(2,3)$.

$\mathrm{Bu}$ olgu takdiminde, kliniğimizde böbreğe migrasyonu olan, proksimal ucu taşlaşmış double-j kateterli bir hastada retrograd intrarenal felksible üreterorenoskop ile tedavi yaklaşımımızı tartıştık.

\section{Olgu Takdimi}

Kırkiki yaşında kadın hastanın 3.5 ay önce sağ üreteropelvik bileşkede mukozaya impakte 1,5 cm taşa fleksible üreterorenoskop (FURS) ile litotripsi uygulama hikayesi mevcuttu. Hastanin preoperatif ince kesit kontrastsız bilgisayarlı tomografi görüntülemesinde sol böbreğin atrofik olduğu saptandı. İşlem sonunda skopi eşliğinde yerleştirilen ve yerinde olduğu doğrulanan double-j stentin distal ucunun 1,5 ay sonra yapılan sistoskopide mesanede olmadığ 1 tespit edildi. Direk üriner sistem grafisinde (DÜSG) double-j kateter distal ucunun mesanede olmadiğ 1 doğrulandı.

Double-j kateterin alınması için, semirijit $9.5 \mathrm{~F}$ üreterorenoskop (URS) ile girildiğinde double-j kateterin distal ucu

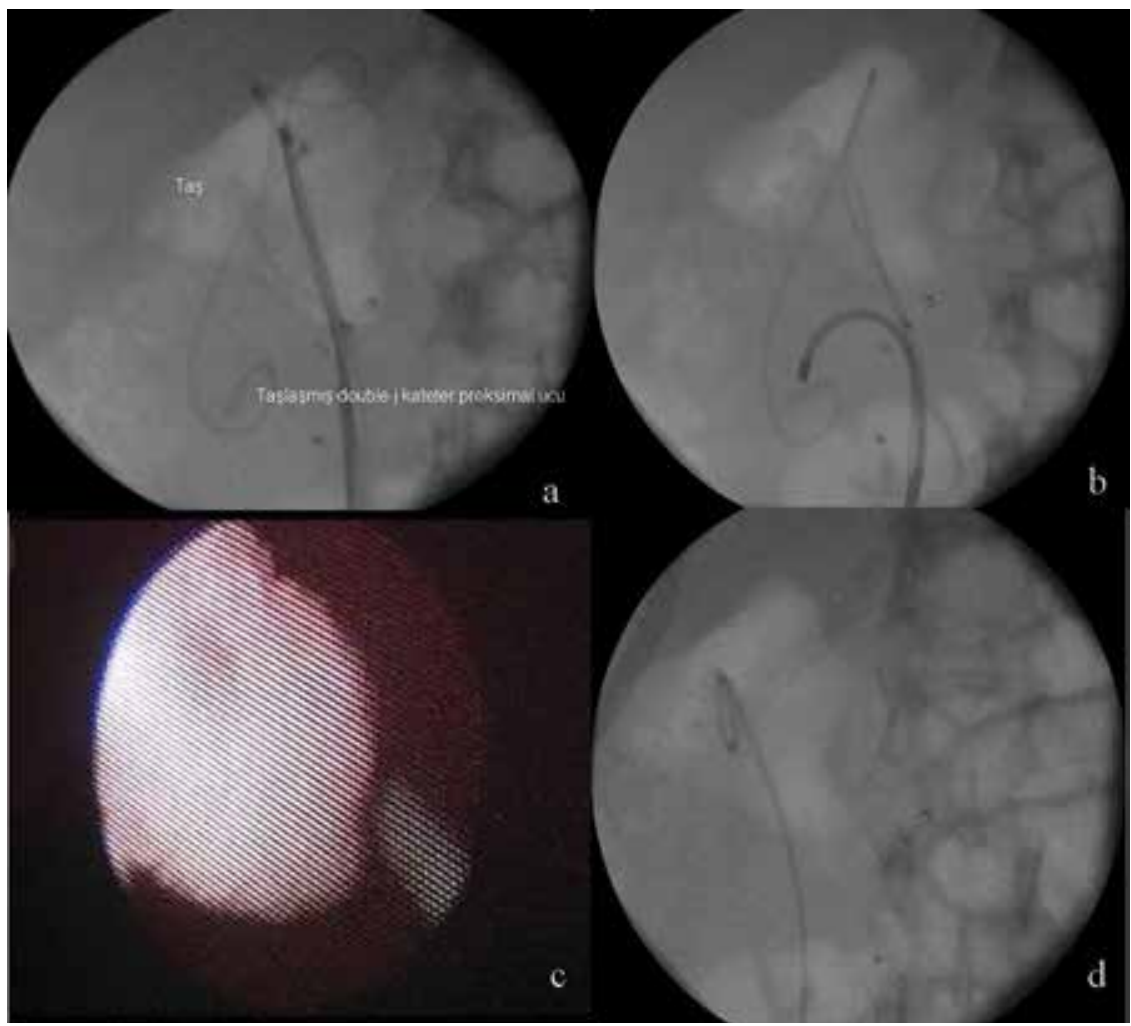

Resim 1. Proksimale migrate olan double j kateterin FURS ile tedavisi a. Böbrek sistemine FURS ile giriş b, c. Kateter proksimal ucundaki taşlaşmış bölgenin ve taşın lazer litotriptör ile tedavisi $\mathbf{d}$. Yeni double $\mathrm{j}$ kateterin takılması ve kontrolü 
üreter orta kesimde gözlendi. Ancak yabancı cisim forsepsi ile kateter çekilemesinde direnç hissedildi. Skopi ile görüntülemesinde double-j kateterin proksimal ucunun taşlaştığ ve komşuluğunda $1 \mathrm{~cm}$ taş olduğu gözlendi.

Kateterin yanından sensör kılavuz tel pelvise gönderildi, semirigid URS çıkarılarak FURS ile renal pelvise ulaşıldı. Bir cm olan taşa ve double-j kateterin proksimal ucundaki taşlaşmış bölgeye Ho-YAG lazer ile litotripsi uygulanarak double-j kateter çıkarıldı. 4,7F $26 \mathrm{~cm}$ double-j kateter yerleştirilerek işleme son verildi (Resim 1). Üç hafta sonra double-j kateteri çekilen hastanın kontrol DÜSG ve üriner ultrasonunda taş saptanmadi.

\section{Tartışma}

Double-j kateterin proksimale migrasyonunda hasta boyu, üreter boyundan kısa kateter seçilmesi literatürde risk faktörü olarak belirtilmekle birlikte vakamızda double-j kateter skopi eşliğinde takılmıştı ve yeri doğrulanmıştı (4). Bununla birlikte son dönemde artan sayıda migrasyonla karşılaşılma nedeninin double-j kateter uçlarındaki yetersiz loop oluşumunun da etkili olabileceğini düşünüyoruz.

Double-j kateterin migrasyonu sik rastlanan bir komplikasyon olmakla birlikte kılavuzların önerdiği standart bir tedavi yöntemi yoktur. Kateterin vücutta bulunma süresi, beraberinde taş bulunması, kateterin distal ucunun seviyesi, distalinde darlık veya king varlığı, uygulamayı yapan kliniğin teknik imkanları gibi birçok etken, çıkarılma sırasındaki yaklaşımın hastaya özel olmasını gerektirmektedir. Double-j kateterin proksimal migrasyonu için literatürde balon dilatatör (5), taşlaşmış kateterlerde SWL uygulaması (6), perkütan (7) veya semirigid URS'u (6). içeren birçok yaklaşım tanımlanmıştır.

Double-j kateterin proksimal ucunun taşlaşmış olması nedeniyle balon dilatör veya semirijid URS yardımıyla distal ucun yabancı cisim forsepsi ile çekilmesi üreter yaralanmasına neden olabileceğinden, bu vakada uygun değildi.

\section{Bu aşamada hangi yaklaşımlar uygun olabilirdi?}

1. İşleme son verip, taşlaşmış bölgeye ve taşa SWL uygulayıp sonrasında semirigid URS ile double-j kateterinin çekilmesi: Bu yöntem daha az invaziv gözükmekle birlikte hastaya ikinci kez anestezi altında müdahale gerekecekti.

2. Să̆ böbreğe perkütan giriş ile taşın kırıması ve aynı yolla double-j'nin alınması: Yeni yayınlanan enkruste kateterlerde \%21 ek işlemsiz, \%34 ikincil işlem ile tüm hastalarda kateterlerin çıkarıldığı bildirilen 25 hastalık seride 24 hastada taşsızlık sağlanmıştı (8). Bu seride unutulmuş double-j kateterlerde dahi, PNL'nin yüksek başarı sağladığı gösterildi. Bizim vakamızda da PNL ile girişimi tercih edilseydi, double-j kateterinin alınmasıyla aynı anda taşa da müdahale edilebilirdi. Ancak $1 \mathrm{~cm}^{\prime}$ lik taş için daha az morbit alternatifleri varken, daha komplike vakalara saklanmasının uygun olacağ öncelikli olarak tercih edilmemiştir.

3. Semirijid URS ile üreter kateterinin proksimaline çıkarak taşı kırıp, double-j kateteri almak: Bu yöntem de taşlaş- mış bir double-j kateterinin yanından semirigid URS ile girişim yapmak üreter komplikasyonları açısından risk oluşturacağından ve double-j kateterin ucundaki taşlaşmış bölgeye ulaşıp taşı kırmak mümkün olmayacağından bu vaka için tercih edilmemiştir.

Bu nedenlerle, bu olguda FURS ile müdahale tercih edilmiştir. Bu yöntemin avantajı PNL'ye göre daha az invaziv olmakla birlikte aynı seansta taşa müdahale ederek kateteri alma imkanı vermesidir. Bu olguda aynı seansta her iki hedefe komplikasyonsuz olarak ulaşılmıştır. Bu işleme karar verilirken birkaç noktaya dikkat edilmelidir; öncelikle üreter çapına ve frajilitesine göre retrograd yoldan FURS ile girişimin riskleri değerlendirmeli ve lazer litoriptör kullanırken kateter kopmasından korunmak için $2 \mathrm{~mm}$ güvenlik mesafesi korunmalıdır (9).

Sonuç olarak proksimale migrate olmuş taşlaşmış double-j kateterin çıkarılmasında, uygun vaka seçimiyle FURS öncellikle tercih edilebilecek minimal invaziv bir tedavi yöntemdir.

\section{Kaynaklar}

1. Finney RP. Experience with new double J ureteral catheter stent. J Urol. 1978 Dec;120(6):678-81.)

2. İsen K, Küpeli B, Sınık Z, Biri H, Şen İ, Bozkırlı İ. Double-J Kateterler: Klinik Kullanım Ve Komplikasyonları Turkiye Klinikleri J Med Sci 1998; 18(1): 54-8

3. Damiano R, Oliva A, Esposito C, De Sio M, Autorino R, D'Armiento M.Early and late complications of double pigtail ureteral stent. Urol Int. 2002; 69(2): 136-40.

4. Breau RH, Norman RW. Optimal prevention and management of proximal ureteral stent migration and remigration.J Urol. 2001 Sep;166(3):890-3.

5. Yap RL, Batler RA, Kube D, Smith ND. Retrieval of migrated ureteral stent by intussusception of ureteral balloon dilator tip. Urology. 2004 Mar;63(3):571-3.

6. Ahallal Y, Khallouk A, El Fassi MJ, Farih MH. Risk factor analysis and management of ureteral double-j stent complications. Rev Urol. 2010; 12(2-3) :e147-51.

7. Bhirud P, Giridhar V., Hegde P.Midureteric knotted stent removed by percutaneous access! Urol Ann. 2012; 4(2): 106-10

8. Pais VM JR, Chew B, Shah O, Hyams ES, Matlaga B, Venkatesh R, Page J, Paterson RF, Arsovska O, Kurtz M, Eisner BH. Percutaneous nephrolithotomy for removal of encrusted ureteral stents: a multicenter study. J Endourol. 2014; 28: 1188-1191.

9. Santa-Cruz RW, Leveillee RJ, Krongrad A.Ex vivo comparison of four lithotripters commonly used in the ureter: what does it take to perforate? J Endourol. 1998 Oct;12(5):417-22.

Yazışma Adresi:

Hakan Kilıçarslan

Uludağ Üniversitesi, Tıp Fakültesi, 16059 Görükle, Bursa

Tel: +90 2244515141

e-mail: hkilicarslan@uludag.edu.tr 